\title{
Validated spectrophotometric methods for determination of Alendronate sodium in tablets through nucleophilic aromatic substitution reactions
}

Mohamed I Walash, Mohamed E-S Metwally, Manal Eid and Rania N El-Shaheny*

\begin{abstract}
Background: Alendronate (ALD) is a member of the bisphosphonate family which is used for the treatment of osteoporosis, bone metastasis, Paget's disease, hypocalcaemia associated with malignancy and other conditions that feature bone fragility. ALD is a non-chromophoric compound so its determination by conventional spectrophotometric methods is not possible. So two derivatization reactions were proposed for determination of ALD through the reaction with 4-chloro-7-nitrobenzo-2-oxa-1,3-diazole (NBD-Cl) and 2,4-dinitrofluorobenzene (DNFB) as chromogenic derivatizing reagents.

Results: Three simple and sensitive spectrophotometric methods are described for the determination of ALD. Method I is based on the reaction of ALD with NBD-Cl. Method II involved heat-catalyzed derivatization of ALD with DNFB, while, Method III is based on micellar-catalyzed reaction of the studied drug with DNFB at room temperature. The reactions products were measured at 472,378 and $374 \mathrm{~nm}$, for methods I, II and III, respectively. Beer's law was obeyed over the concentration ranges of 1.0-20.0, 4.0-40.0 and 1.5-30.0 $\mathrm{\mu g} / \mathrm{mL}$ with lower limits of detection of $0.09,1.06$ and $0.06 \mathrm{\mu g} / \mathrm{mL}$ for Methods I, II and III, respectively. The proposed methods were applied for quantitation of the studied drug in its pure form with mean percentage recoveries of $100.47 \pm 1.12,100.17 \pm$ 1.21 and $99.23 \pm 1.26$ for Methods I, II and III, respectively. Moreover the proposed methods were successfully applied for determination of ALD in different tablets. Proposals of the reactions pathways have been postulated.

Conclusion: The proposed spectrophotometric methods provided sensitive, specific and inexpensive analytical procedures for determination of the non-chromophoric drug alendronate either per se or in its tablet dosage forms without interference from common excipients.
\end{abstract}

\section{Graphical abstract}

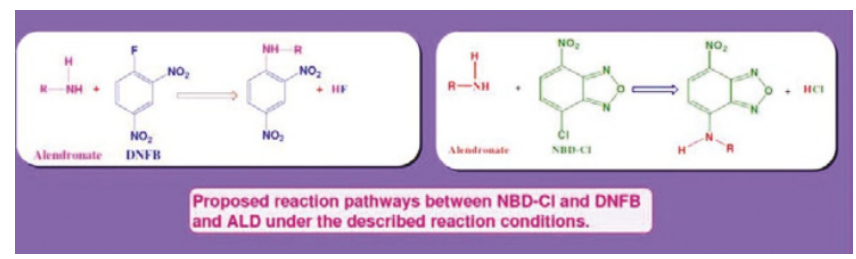

Keywords: Spectrophotometry, Alendronate, NBD-Cl, DNFB, Micellar-catalysis, Tablets

\footnotetext{
* Correspondence: rania_n2010@yahoo.com

Department of Analytical Chemistry, Faculty of Pharmacy, University of Mansoura, Mansoura 35516, Egypt
} 


\section{Background}

Bisphosphonates is the name given to a group of drugs characterized by a geminal bisphosphonate bond [1] From the clinical point of view, bisphosphonates are used for the treatment of osteoporosis, bone metastasis, Paget's disease, hypocalcaemia associated with malignancy and other conditions that feature bone fragility [2].

Among bisphosphonates, one of the most popular first-line drugs is alendronate sodium trihydrate (ALD). ALD is designated chemically as (4-amino-1-hydroxybutylidene) biphosphonic acid monosodium salt trihydrate [3] (Figure 1). The two phosphonic groups per molecule lend a strongly ionic character to ALD and increased polarity. Additionally, ALD does not possess an appreciable chromophore; hence its determination by ordinary spectrophotometric methods is not possible.

ALD is the subject of a monograph in both the British pharmacopoeia (BP) [3] and the United States Pharmacopoeia (USP) [4]. The BP [3] describes an HPLC method with refractive index detection for determination of ALD in its pure form, while The USP [4] recommends an HPLC method with UV-detection after derivatization with 9-fluorenylmethyl chloroformate for its determination, whether in its pure form and in tablets. Several methods have been presented in the literature for the determination of ALD. These include spectrophotometry through complex formation $[5,6]$, oxidation with ceric (IV) sulfate [7] and derivatization of its free primary amino group $[7,8]$. Also the molybdovanadate approach was employed for the determination of ALD in tablets by spectrophotometry [9]. Furthermore, titrimetry [10-12], liquid chromatography with different modes of detection [9,13-23], capillary electrophoresis [24-26] and stopped flow spectrofluorimetric methods [27] have been applied for the determination of ALD.

Since ALD has no functional group that enables absorption in the UV-visible region, so we decided to analyze the drug through derivatization reactions. In this approach, two different labeling agents, namely; 4chloro-7-nitrobenzo-2-oxa-1,3-diazole (NBD-Cl) and 2,4-

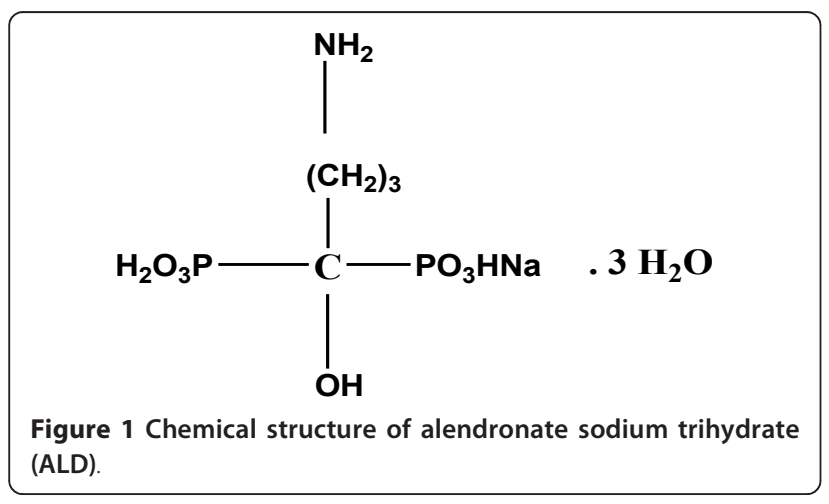

dinitrofluorobenzene (DNFB, Sanger's reagent) have been used in derivatization reactions based on their reaction with the free primary amino group of ALD.

Both reagents are well known to react with primary and secondary amines forming stable condensation colored products [28]. NBD-Cl, as an electroactive halide reagent, was first introduced as an analytical reagent for the determination of some amines and amino acids. In recent reports, NBD-Cl was further used as a chromogenic reagent for the determination of some primary and secondary amines [29-34]. DNFB has been applied as a chromophore reactant in the spectrophotometric determination of some compounds. The reaction of DNFB with amines proceeds very slowly at room temperature. Such reaction could be catalyzed by heating $[33,35,36]$ or by addition of micellar solution [37-39].

The aim of the present study was to optimize the reaction of ALD with both $\mathrm{NBD}-\mathrm{Cl}$ and DNFB. The reaction of ALD with DNFB was enhanced by either heating at $60^{\circ} \mathrm{C}$ or by the addition of cetrimide as a cationic surfactant to the reaction mixture. The applicability of the developed methods was evaluated through the determination of ALD in pure form and tablet formulations.

\section{Experimental}

\section{Instruments}

-A Shimadzu UV-Visible 1601 PC spectrophotometer (Kyoto, Japan) was used for spectrophotometric measurements (P/N 206-67001). The recording range was 0-1.0

-A consort NV P901 digital pH meter (Belgium) calibrated with standard buffers was used for checking the $\mathrm{pH}$ of the buffer solutions used.

\section{Reagents and materials}

All the reagents used were of analytical grade and distilled water was used throughout the work.

-Amriya Pharm. Ind. CO. (Alexandria, Egypt) kindly supplied a pure sample of alendronate sodium trihydrate (with a purity of $100.55 \%$ as determined by the comparison method [7]) (Batch \# AAS0400010).

-NBD-Cl (Aldrich Chemical Co. Ltd., USA) was freshly prepared as $0.2 \%(\mathrm{w} / \mathrm{v})$ methanolic solution.

-DNFB (Fluka chemica, USA) solution was freshly prepared as $0.3 \%(\mathrm{v} / \mathrm{v})$ in methanol, for both methods II and III.

-Cetyltrimethylammonium bromide (cetrimide) was obtained from Merck (Darmstadt, Germany), 1\% (w/v) aqueous solution was prepared.

-Sodium dodecyl sulphate (SDS, 95\%) was obtained from Winlab (Middlesex, England). 1\% (w/v) aqueous solution was prepared.

-Methanol, concentrated hydrochloric acid, sodium hydroxide, boric acid and tween- $80(1 \% \mathrm{w} / \mathrm{v}$ aqueous 
solution) were purchased from El-Nasr Pharm. Chem. Co. (ADWIC), Abu Zabaal, Egypt.

-Borate buffer solutions $(0.2 \mathrm{M})$ were prepared by mixing appropriate volumes of $0.2 \mathrm{M}$ boric acid and $0.2 \mathrm{M} \mathrm{NaOH}$ and adjusting the $\mathrm{pH}$ to $10.0,10.5$ and 10.7 using a $\mathrm{pH}$ meter [40].

-The following tablets containing the drug were purchased from local pharmacies:

- Osteonate ${ }^{\circledR}$ tablets (batch \# 060181) labeled to contain $10 \mathrm{mg}$ alendronic acid equivalent to $13.05 \mathrm{mg}$ alendronate sodium trihydrate, product of the Egyptian Co. For Chemicals and Pharmaceuticals (ADWIA) S.A. E, $10^{\text {th }}$ of Ramadan City, Egypt.

- Alendex ${ }^{\circledR}$ tablets (batch \# 6038) labeled to contain $40 \mathrm{mg}$ of alendronic acid equivalent to $52.2 \mathrm{mg}$ alendronate sodium trihydrate, product of Uni Pharma Co., Al Obour City, Cairo, Egypt.

\section{Standard solutions}

Standard solutions of ALD were prepared by dissolving 20.0, 40.0 and $30.0 \mathrm{mg}$ of ALD in $100 \mathrm{~mL}$ distilled water for methods I, II and III, respectively. These solutions were stable for at least 10 days when stored in the refrigerator. Working solutions were obtained by appropriate dilution.

\section{General recommended procedures Construction of calibration graphs}

i. Method I To a set of $10-\mathrm{mL}$ volumetric flasks, aliquot volumes containing the drug in the working concentration range of $1.0-20.0 \mu \mathrm{g} / \mathrm{mL}$ were quantitatively transferred. To each flask $1 \mathrm{~mL}$ of borate buffer ( $\mathrm{pH} 10.7)$ followed by $1.2 \mathrm{~mL}$ of $\mathrm{NBD}-\mathrm{Cl}$ solution $(0.2 \% \mathrm{w} / \mathrm{v})$ were added and mixed well. The solutions were heated in thermostatically controlled water bath at $70^{\circ} \mathrm{C}$ for $25 \mathrm{~min}$. The reaction was stopped by cooling under tap water, then $0.2 \mathrm{~mL}$ of concentrated $\mathrm{HCl}$ was added and the solutions were made up to volume with methanol. The absorbance was measured at $472 \mathrm{~nm}$ against a reagent blank. The calibration graph was constructed by plotting the absorbance versus the final concentration of the drug $(\mu \mathrm{g} / \mathrm{mL})$. Alternatively, the corresponding regression equation was derived.

ii. Method II To a set of $10-\mathrm{mL}$ volumetric flasks, aliquot volumes containing the drug over the working concentration range of 4.0-40.0 $\mu \mathrm{g} / \mathrm{mL}$ were quantitatively transferred. To each flask $1 \mathrm{~mL}$ of borate buffer ( $\mathrm{pH} 10.5)$ followed by $1.2 \mathrm{~mL}$ of DNFB solution $(0.3 \% \mathrm{v} / \mathrm{v})$ were added and mixed well. The solutions were heated in thermostatically controlled water bath at $60^{\circ} \mathrm{C}$ for $15 \mathrm{~min}$. The reaction was stopped by cooling under tap water, then $0.2 \mathrm{~mL}$ of concentrated $\mathrm{HCl}$ was added and the flasks were made up to volume with water. The absorbance was measured at $378 \mathrm{~nm}$ against a reagent blank. The absorbance was plotted versus the final concentration of the drug $(\mu \mathrm{g} / \mathrm{mL})$ to obtain the calibration graph. Alternatively, the corresponding regression equation was derived. iii. Method III To a set of $10-\mathrm{mL}$ volumetric flasks, aliquot volumes containing the drug over the working concentration range of $1.5-30.0 \mu \mathrm{g} / \mathrm{mL}$ were quantitatively transferred. A volume of $1 \mathrm{~mL}$ of $0.2 \mathrm{M}$ borate buffer ( $\mathrm{pH}$ 10.0) was added to each flask followed by 0.8 $\mathrm{mL}$ of $1 \% \mathrm{w} / \mathrm{v}$ cetrimide solution and $1 \mathrm{~mL}$ of DNFB solution $(0.3 \% \mathrm{v} / \mathrm{v})$. The solutions were mixed well and left at room temperature for $5 \mathrm{~min}$ before the addition of $0.2 \mathrm{~mL}$ of concentrated $\mathrm{HCl}$ to all the flasks. The volumes were completed using distilled water. The absorbance was measured at $374 \mathrm{~nm}$ against a reagent blank. The absorbance was plotted versus the final concentration of the drug $(\mu \mathrm{g} / \mathrm{mL})$ to obtain the calibration graph. Alternatively, the corresponding regression equation was derived.

\section{Assay procedure for tablets}

Ten tablets were accurately weighed, finely powdered and mixed well. A portion of the powder equivalent to 20.0 $\mathrm{mg}(\operatorname{method} \mathrm{I}), 40.0 \mathrm{mg}$ (method II) and $30.0 \mathrm{mg}$ (method III) of ALD was transferred into100-mL volumetric flasks, about $80 \mathrm{~mL}$ distilled water was added to each flask and they were sonicated for $15 \mathrm{~min}$. The volume was completed with water, mixed and filtered. Aliquots covering the working concentration ranges cited in Table 1 were transferred into $10-\mathrm{mL}$ volumetric flasks. The procedures described under "Construction of calibration graphs" were followed adopting any of the three methods. The nominal contents of the tablets were calculated using the corresponding regression equation.

\section{Results and discussion}

\section{Method I}

ALD is a primary aliphatic amino derivative that was found to react with NBD-Cl with the formation of a yellow adduct. Under the described experimental conditions, the yellow adduct has a characteristic absorption spectrum with maximum absorbance at $472 \mathrm{~nm}$ as shown in Figure 2.

\section{Study of experimental parameters}

The experimental conditions were studied by varying each parameter individually and noting its effect on the absorbance of the product.

i. Effect of pH and volume of buffer The $\mathrm{pH}$ dependence of the system was studied over the range of 7.0-11.0 using $0.2 \mathrm{M}$ borate buffer. Maximum absorption intensity was obtained at $\mathrm{pH} 10.7 \pm 0.2$. Therefore, $\mathrm{pH} 10.7$ was chosen as the optimum pH for such study (Figure 3). Maximum absorption intensity was obtained upon using $1 \pm 0.5 \mathrm{~mL}$ of the buffer solution (Figure 4). Other buffers 
Table 1 Analytical performance data for the proposed methods

\begin{tabular}{|c|c|c|c|}
\hline Parameter & Method I & Method II & Method III \\
\hline Concentration range $(\mu \mathrm{g} / \mathrm{mL})$ & $1.0-20.0$ & $4.0-40.0$ & $1.5-30.0$ \\
\hline Limit of detection (LOD) $(\mu \mathrm{g} / \mathrm{ml})$ & 0.09 & 1.06 & 0.06 \\
\hline Limit of quantification (LOQ) $(\mu \mathrm{g} / \mathrm{mL})$ & 0.26 & 3.2 & 0.18 \\
\hline Correlation coefficient $(r)$ & 0.9998 & 0.9995 & 0.9996 \\
\hline Slope & 0.0392 & 0.0150 & 0.0384 \\
\hline Intercept & 0.0167 & 0.0134 & -0.0401 \\
\hline Standard deviation of the residuals (Sy/x) & $7.80 \times 10^{-3}$ & $6.74 \times 10^{-3}$ & $1.00 \times 10^{-2}$ \\
\hline Standard deviation of the intercept (Sa) & $1 \times 10^{-3}$ & $4.80 \times 10^{-3}$ & $6.98 \times 10^{-4}$ \\
\hline Standard deviation of the slope (Sb) & $4.67 \times 10^{-4}$ & $2.36 \times 10^{-4}$ & $4.80 \times 10^{-4}$ \\
\hline$\%$ RSD & 1.11 & 1.21 & 1.27 \\
\hline$\%$ Error $(\% \mathrm{RSD} / \sqrt{ } \mathrm{n})$ & 0.45 & 0.54 & 0.52 \\
\hline Molar absorptivity $(\varepsilon)(\mathrm{l} / \mathrm{mol} . / \mathrm{cm})$. & $1.32 \times 10^{4}$ & $5.2 \times 10^{3}$ & $1.22 \times 10^{4}$ \\
\hline
\end{tabular}

having the same $\mathrm{pH}$ value such as Britton Robinson buffer and phosphate buffer were attempted and compared with $0.2 \mathrm{M}$ borate buffer. Borate buffer was found to be superior to others as revealed by the high absorption intensity. This different response to different buffers may be attributed to the slow rate of hydrolysis of NBD-Cl to NBD-OH in borate buffer. This result is in agreement with that of Miyano H. et al. [41].

ii. Effect of concentration of NBD-Cl solution The influence of NBD-Cl concentration was studied using different volumes of $0.2 \% \mathrm{w} / \mathrm{v}$ solution of the reagent. It was found that increasing volumes of the reagent produce a

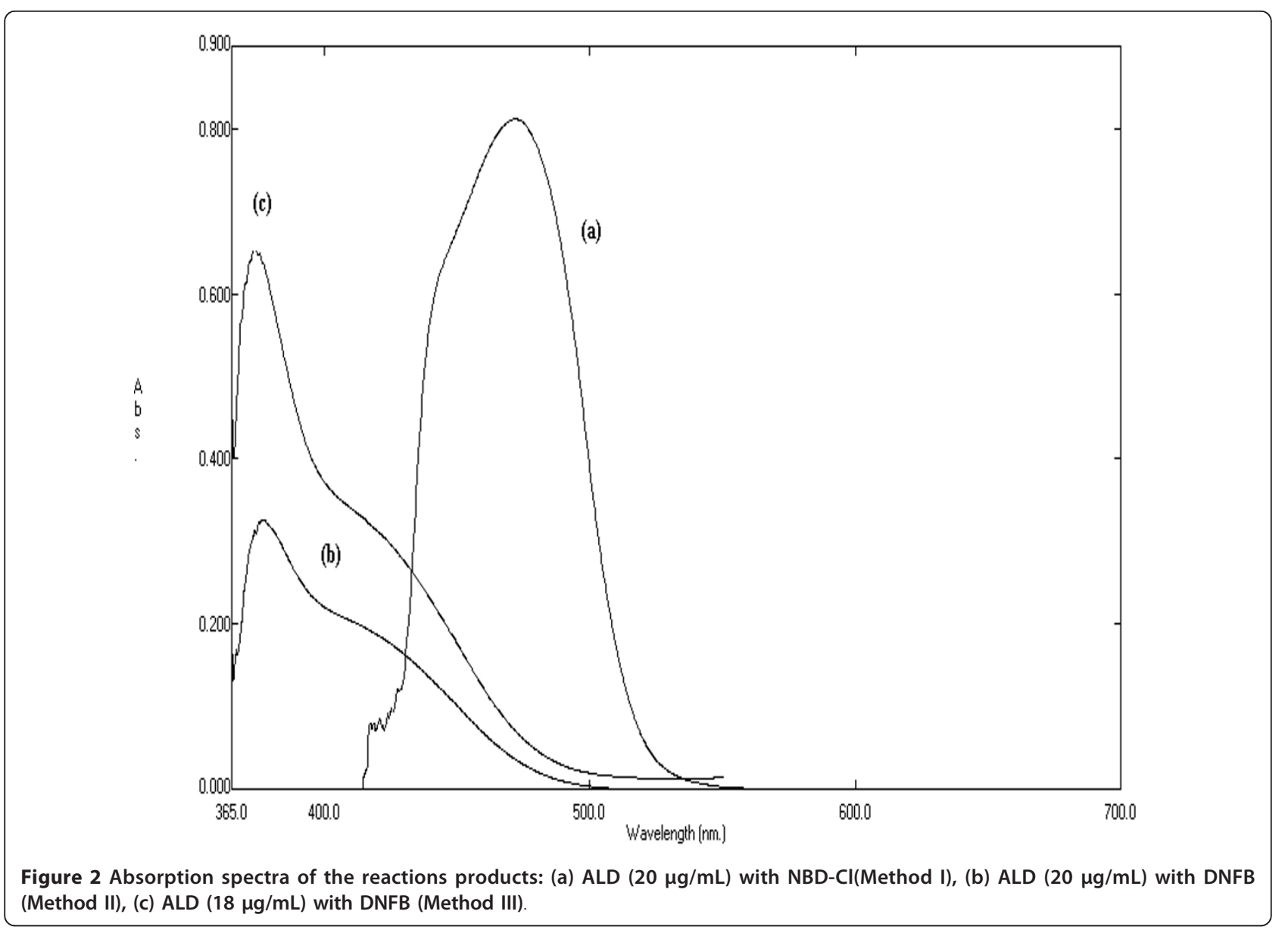




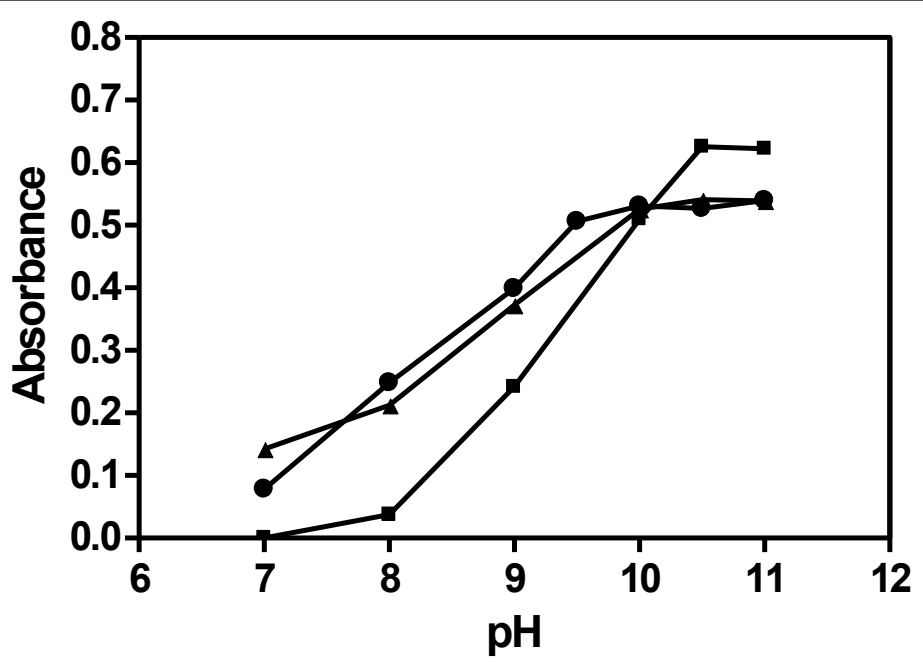

Figure 3 Effect of the $\mathrm{pH}$ of $0.2 \mathrm{M}$ borate buffer on the reaction of: - ALD (15 $\mu \mathrm{g} / \mathrm{mL})$ with NBD-Cl, $\triangle$ ALD $(40 \mu \mathrm{g} / \mathrm{mL})$ with DNFB (method II), • ALD (15 $\mu \mathrm{g} / \mathrm{mL})$ with DNFB (method III).

proportional increase in the absorption intensity up to $1 \mathrm{~mL}$. However, no further increase in the absorption intensity was observed upon increasing the volume of the reagent up to $1.5 \mathrm{~mL}$, after which further increase produced a gradual decrease in the absorption intensity. Therefore, $1.2 \mathrm{~mL}$ of $0.2 \% \mathrm{w} / \mathrm{v} \mathrm{NBD}-\mathrm{Cl}$ solution was chosen as the optimal volume of the reagent (Figure 5). The absorption value of the hydrolysis product of NBD-Cl, namely, 4-hydroxy-7-nitro-benzo-2-oxa-1,3-diazole $(\mathrm{NBD}-\mathrm{OH})$, is quenched by decreasing the $\mathrm{pH}$ of the reaction medium to less than 1 by adding $0.2 \mathrm{~mL}$ of concentrated $\mathrm{HCl}$. Therefore, acidification of the reaction mixture prior to measurement of the absorbance value remarkably decreased the background absorbance due to the formation of NBD-OH without affecting the drugreagent adduct, hence the sensitivity was increased [42].

iii. Effect of heating temperature and heating time Preliminary studies revealed that the reaction rate was very slow at room temperature. In this study, the reaction was performed at different temperatures for various time intervals. As it is seen in Figure 6A, the reaction was completed at $70^{\circ} \mathrm{C}$ within $25 \pm 5 \mathrm{~min}$. Increasing the temperature to $80^{\circ} \mathrm{C}$ resulted in an apparent decrease in the absorption intensity.

iv. Effect of diluting solvent The effect of diluting solvent was tested using different solvents viz water, methanol, acetone, acetonitrile, dimethylformamide and isopropanol. Using water as diluting solvent gives the highest absorbance value. However, the reproducibility upon using this diluting solvent was found to be adversely affected. Of all the diluting solvents studied, methanol was chosen as the best one since it gave reasonable absorption intensity with maximum product stability. v. Effect of time on the stability of the formed adduct Regarding the stability of the produced derivative, it was found to be stable at room temperature for approximately $1 \mathrm{~h}$ after which it faded slowly.

\section{Method II}

The analytical applications of 2,4-dinitrofluorobenzene (DNFB) for the assay and characterization of specific functional groups such as primary and secondary amines, phenols, thiols and imidazoles have been established by Connor [43]. In the present work, DNFB reacts through a nucleophilic aromatic substitution reaction with the primary aliphatic amino group of ALD in aqueous alkaline medium. The reaction between ALD and DNFB is very slow at room temperature and required heating to speed it up. A yellow colored product peaking at $378 \mathrm{~nm}$ is produced (Figure 2).

\section{Study of experimental parameters}

The experimental conditions for the derivatization reaction were optimized by the univariate method (changing one parameter at each step).

i. Effect of pH and volume of buffer The reaction was investigated over the $\mathrm{pH}$ range of 7.0-11.0 using $0.2 \mathrm{M}$ borate buffer. The product showed the highest absorption in buffer of pH $10.5 \pm 0.5$ (Figure 3). Therefore, $\mathrm{pH}$ 10.5 was selected as the optimum $\mathrm{pH}$ for such reaction. It was found that increasing the volume of the buffer produces a corresponding increase in the absorbance value of the reaction product up to $0.5 \mathrm{~mL}$, and it remained constant up to $1.5 \mathrm{~mL}$ (Figure 4). Therefore, $1 \mathrm{~mL}$ was chosen as the optimum buffer volume.

ii. Effect of concentration of DNFB solution The influence of the concentration of DNFB was studied using 


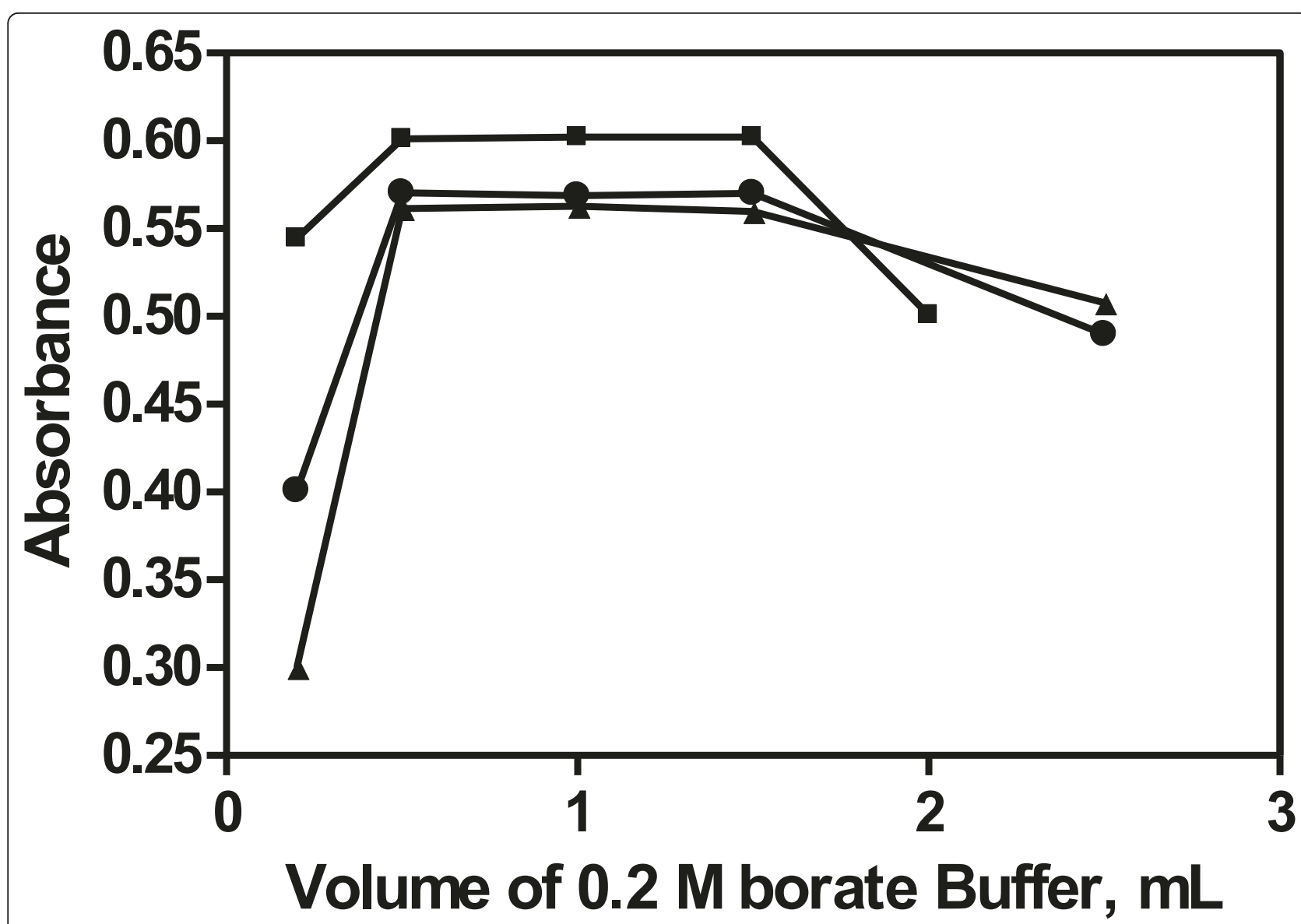

Figure 4 Effect of the volume of $0.2 \mathrm{M}$ borate buffer on the reaction of: $\mathrm{ALD}(15 \mu \mathrm{g} / \mathrm{mL})$ with NBD-Cl, $\triangle$ ALD (40 $\mu \mathrm{g} / \mathrm{mL})$ with DNFB (method II), • ALD (15 $\mu \mathrm{g} / \mathrm{mL})$ with DNFB (method III).

different volumes of $0.3 \% \mathrm{v} / \mathrm{v}$ solution of the reagent. It was found that increasing volumes of the reagent produce a proportional increase in the absorption intensity up to $1 \mathrm{~mL}$. However, no further increase in the absorption intensity was observed upon increasing the volume of the reagent up to $1.5 \mathrm{~mL}$, after which further increase produces a gradual decrease in the absorption intensity. Therefore, $1.2 \mathrm{~mL}$ of $0.3 \% \mathrm{v} / \mathrm{v}$ DNFB solution was chosen as the optimal volume of the reagent (Figure 5). To remove the excess reagent interference in the absorbance measurement of the reaction product, this excess was acid-hydrolyzed to colorless 2,4-dinitrophenol by adding $0.2 \mathrm{~mL}$ of concentrated $\mathrm{HCl}$ allowing the measurement of ALD-DNFB derivative which remains stable.

iii. Effect of heating temperature and heating time In order to obtain the highest and most stable absorbance, the effect of the reaction time and heating temperature was investigated (Figure 6B). It was found that the reaction proceeds very slowly at room temperature. A gradual increase in the heating temperature produced a significant increase in the absorbance of the reaction product up to $70^{\circ} \mathrm{C}$. Heating at $80^{\circ} \mathrm{C}$ resulted in precipitation of the reagent. Therefore, the reaction was carried out at $60^{\circ} \mathrm{C}$ for $15 \mathrm{~min}$, which was adequate for complete color development.

iv. Effect of diluting solvent The effect of different diluting solvent was tested using water, methanol, acetone, acetonitrile, dimethylformamide, dimethylsulfoxide and isopropanol. Using water as diluting solvent gives highest absorbance value and best peak shape. Additionally, the spectrum for ALD-DNFB in this solvent was found to be shifted about $10 \mathrm{~nm}$ toward higher wavelength compared to those in methanol, acetone, isopropanol and acetonitrile. On the other hand, dilution with dimethylformamide and dimethylsulfoxide resulted in high blank reading. Finally, water was chosen as the best diluting solvent.

v. Effect of time on the stability of the formed adduct The reaction product was found to be stable for at least $60 \mathrm{~min}$ at room temperature.

\section{Method III}

According to the literature, the reaction of DNFB with amines could be performed at room temperature or 


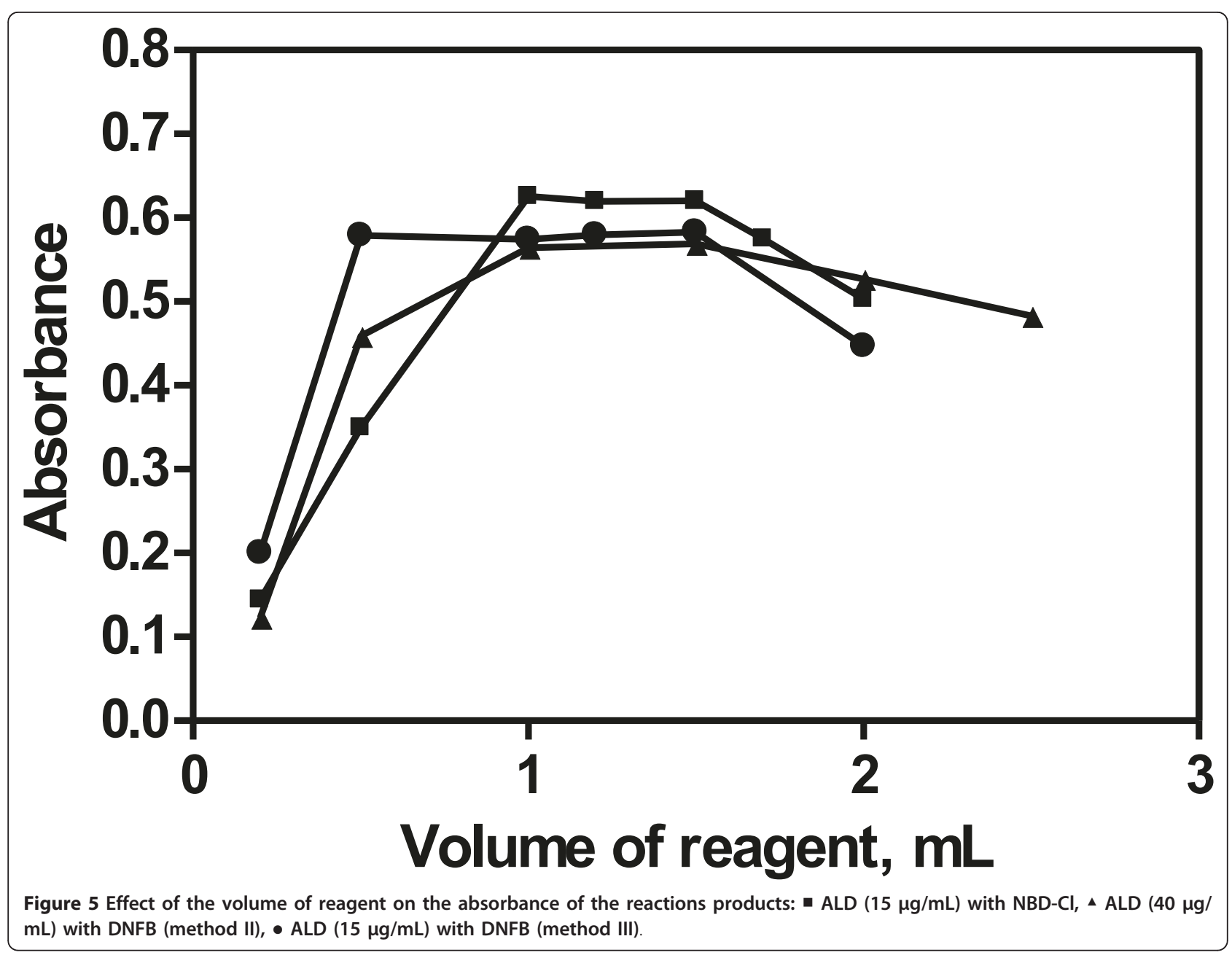

even at low temperature and in a short time through micellar catalysis. It was

found that the micellar catalysis is useful not only in speeding up the slow reaction of DNFB with ALD, and thus adapting the time scale of the experiment, but also in softening the experimental conditions required to carry out the reaction, e.g. reducing the temperature and the time for completion of the reaction. In addition, the increase in the rate of the reaction is accompanied by an increase in the apparent molar absorptivity, and therefore the sensitivity and reliability of the procedure adapted.

Study of experimental parameters

The experimental conditions for the derivatization reaction were optimized by the univariate method.

i. Effect of $\mathrm{pH}$ and volume of buffer The reaction was investigated over the $\mathrm{pH}$ range of 7.0-11.0 using $0.2 \mathrm{M}$ borate buffer. It was found that increasing the $\mathrm{pH}$ resulted in a corresponding increase in the absorbance of the reaction product up to $\mathrm{pH} 9.5$ after which it remained constant. Therefore, $\mathrm{pH} 10.0$ was chosen as the optimal pH throughout this study (Figure 3). It was found that increasing the volume of the buffer produces a corresponding increase in the absorbance value of the reaction product up to $0.5 \mathrm{~mL}$, and it remained constant up to $1.5 \mathrm{~mL}$ (Figure 4). Therefore, $1 \mathrm{~mL}$ was chosen as the optimum buffer volume.

ii. Effect of concentration of DNFB solution The influence of the concentration of DNFB was studied using different volumes of $0.3 \% \mathrm{v} / \mathrm{v}$ solution of the reagent. It was found that increasing volumes of the reagent produce a proportional increase in the absorption intensity up to $0.5 \mathrm{~mL}$. However, no further increase in the absorption intensity was observed upon increasing the volume of the reagent up to $1.5 \mathrm{~mL}$, after which further increase produces a gradual decrease in the absorption intensity. Therefore, $1.0 \mathrm{~mL}$ of $0.3 \% \mathrm{v} / \mathrm{v}$ DNFB solution was chosen as the optimum volume of the reagent (Figure 5). To remove the excess reagent interference in the absorbance measurement of the reaction product, 0.2 $\mathrm{mL}$ of concentrated $\mathrm{HCl}$ was added.

iii. Effect of concentration of cetrimide The optimal cetrimide concentration required to catalyze the reaction 


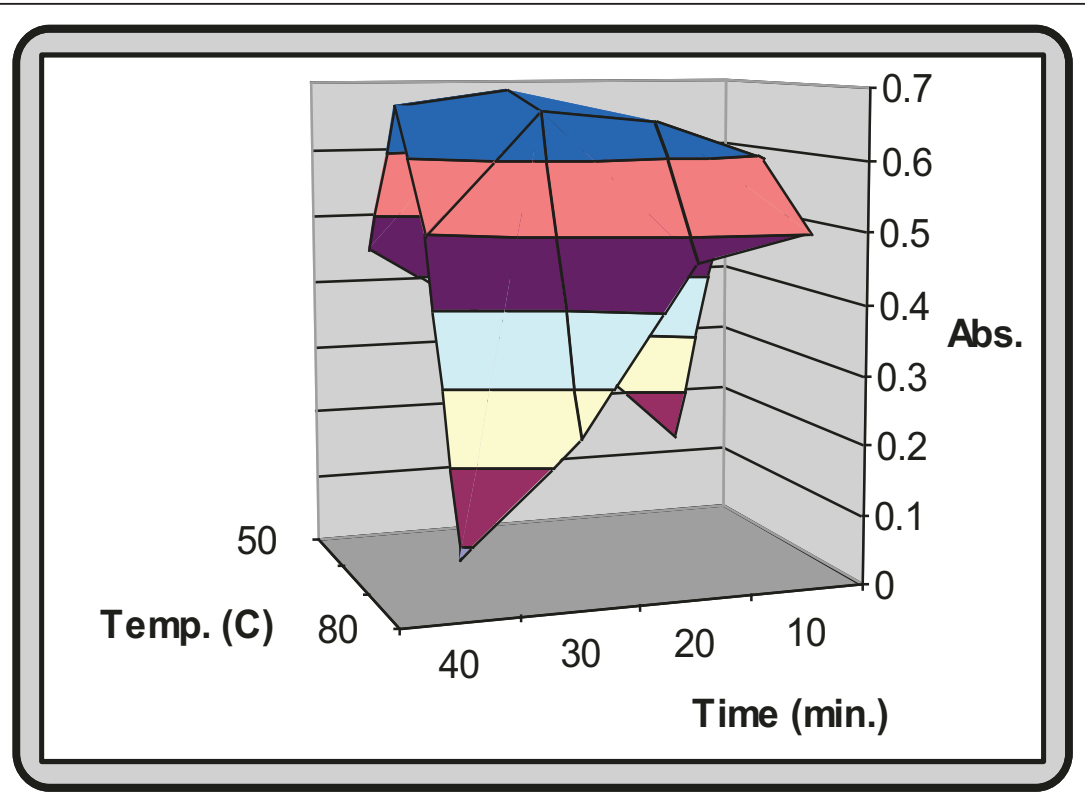

(A)

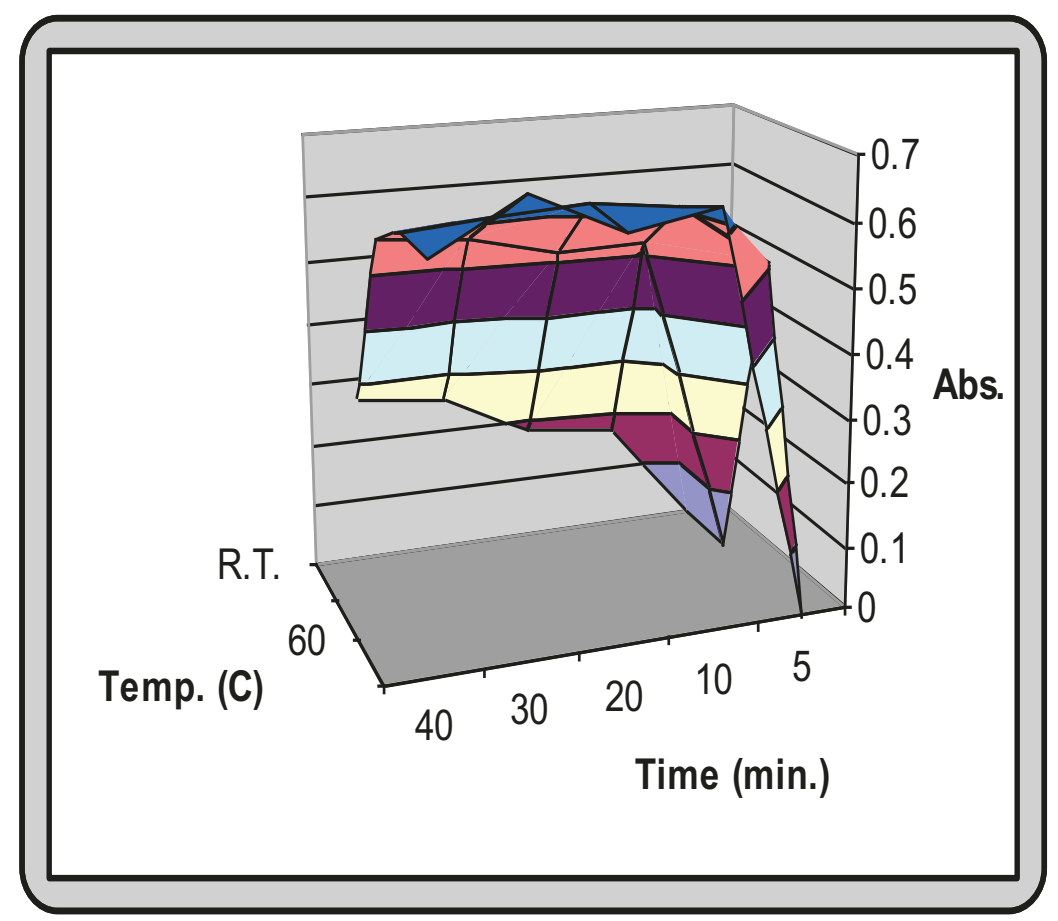

(B)

Figure 6 Effect of the heating time on the proposed reactions at different temperature settings. (A) ALD (15 $\mu \mathrm{g} / \mathrm{mL})$ with NBD-Cl, (B) $\operatorname{ALD}(40 \mu \mathrm{g} / \mathrm{mL})$ with DNFB (method II).

of ALD with DNFB was determined by adding increasing volumes of $1 \% \mathrm{w} / \mathrm{v}$ cetrimide solution to the reaction mixture. It was found that $0.5-1.2 \mathrm{ml}$ of $1 \%$ cetrimide solution was suitable to develop the absorbance to its maximum intensity. The absorption intensity decreased with further increase in the volume of cetrimide solution. $0.8 \mathrm{~mL}$ of $1 \% \mathrm{w} / \mathrm{v}$ aqueous cetrimide solution was chosen as optimal volume throughout this work (Figure 7). 


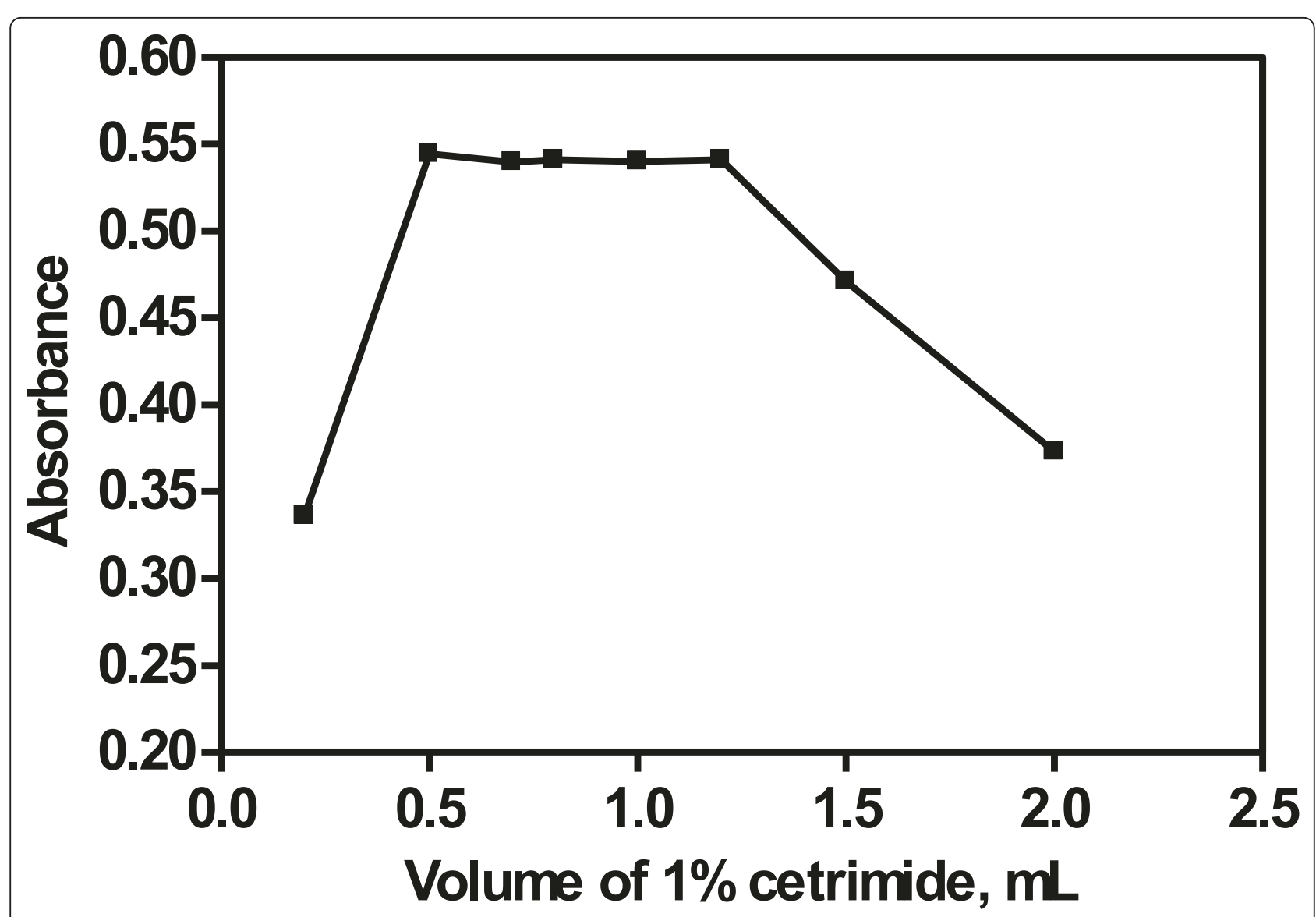

Figure 7 Effect of the volume of $1 \%$ cetrimide on the absorbance of the reaction product of ALD (15 $\mu \mathrm{g} / \mathrm{mL}) \mathrm{with} \mathrm{DNFB} \mathrm{(method} \mathrm{III)}$

About 5.5-folds increase of the sensitivity was obtained in presence of cetrimide relative to that in the non-micellar aqueous medium at room temperature for longer time (30 min) (Figure 8).

When cetrimide was replaced by anionic surfactant (SDS) or nonionic surfactant (tween 80) no enhancement of the sensitivity was observed relative to the nonmicellar medium.

iv. Effect of diluting solvent The effect of diluting solvents other than water such as methanol, acetone, acetonitrile, dimethylformamide, dimethylsulfoxide and isopropanol was also investigated to obtain the maximum color intensity. It was found that water, isopropanol and acetonitrile are of similar effect. Meanwhile, methanol, acetone, dimethylformamide and dimethylsulfoxide slightly decreased the color intensity. Water was selected as the optimal diluting solvent.

v. Effect of time on the formation and stability of the formed adduct Maximum color development was obtained within $5 \mathrm{~min}$ of mixing the reactants (Figure 8), and was stable for at least 60 min thereafter.

A summary for the optimization study of the variables affecting the three proposed methods is given in Table 2.
Validation of the proposed methods

The validity of the proposed methods was tested regarding linearity, range, limit of quantitation, limit of detection, accuracy, precision, robustness and specificity according to ICH Q2(R1) recommendations [44].

\section{Linearity and range}

The calibration graphs obtained by plotting the values of the absorbance versus the final concentrations $(\mu \mathrm{g} / \mathrm{mL})$ were found to be rectilinear over the concentration ranges cited in Table 1 . The proposed methods were evaluated for the accuracy as percent relative error (\% Er) and the precision as percent relative standard deviation (\% RSD) (Table 1). The validity of the proposed methods were proven by statistical evaluation of the regression line, using the standard deviation of the residuals $\left(S_{y / x}\right)$, the standard deviation of the intercept $\left(S_{a}\right)$ and standard deviation of the slope $\left(S_{b}\right)$. The results are abridged in Table 1. The small values of the figures indicate low scattering of the points around the calibration line.

\section{Limits of quantitation and limits of detection}

The limits of quantitation (LOQ) were determined by establishing the lowest concentrations that can be 


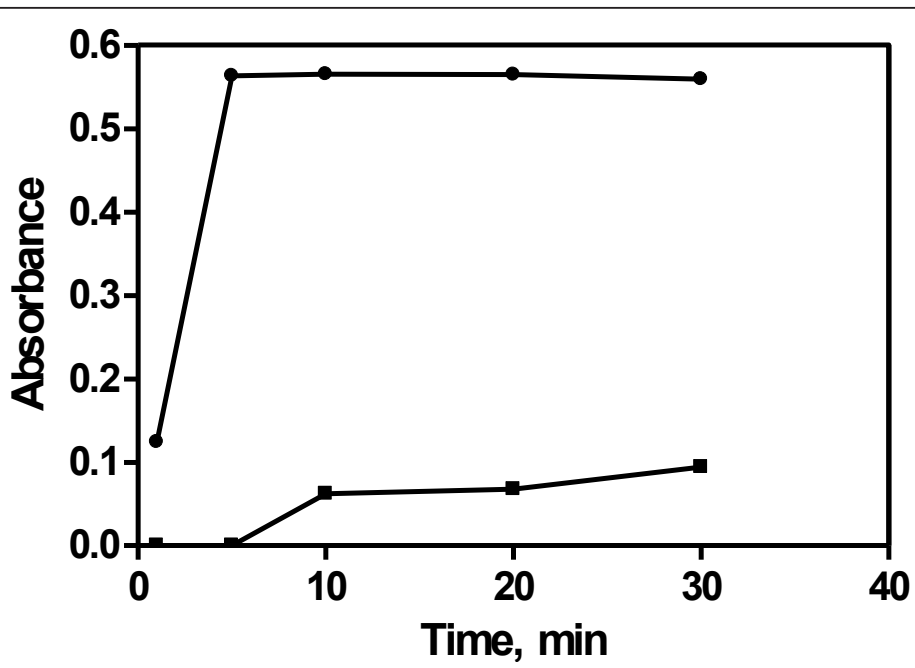

Figure 8 Effect of the time on the reaction of ALD (15 $\mu \mathrm{g} / \mathrm{mL})$ with DNFB at room temperature: $\bullet$ in presence of $0.8 \mathrm{~mL}$ of $1 \% \mathrm{w} / \mathrm{v}$ cetrimide solution. in absence of cetrimide.

measured according to ICH Q2 (R1) recommendation [44] below which the calibration graph is non linear. The limits of detection (LOD) were determined also by evaluating the lowest concentrations of the analytes that can be readily detected. The results are summarized in Table 1.

LOQ and LOD were calculated according to the following equations [44]:

$$
\begin{aligned}
& \mathrm{LOQ}=10 \mathrm{~S}_{\mathrm{a}} / \mathrm{b} \\
& \mathrm{LOD}=3.3 \mathrm{~S}_{\mathrm{a}} / \mathrm{b}
\end{aligned}
$$

Where $S_{a}$ is the standard deviation of the intercept of regression line, and $b$ is the slope of the regression line.

The obtained sensitivities were comparable to those reported for other analytical techniques used for determination of ALD.

Table 2 Assay parameters for the determination of ALD by the three proposed methods

\begin{tabular}{lccc}
\hline parameter & Method I & Method II & Method III \\
\hline Standard conc. $(\boldsymbol{\mu g} / \mathrm{mL})$ & 200 & 400 & 300 \\
Borate buffer $\mathbf{p H}$ & $10.7 \pm 0.2$ & $10.5 \pm 0.5$ & $10.0 \pm 0.5$ \\
Borate buffer volume $(\mathrm{mL})$ & $1 \pm 0.5$ & $1 \pm 0.5$ & $1 \pm 0.5$ \\
Reagent conc. & $0.2 \% \mathrm{~W} / \mathrm{V}$ & $0.3 \% \mathrm{~V} / \mathrm{V}$ & $0.3 \% \mathrm{v} / \mathrm{V}$ \\
Reagent volume $(\mathrm{mL})$ & $1.2 \pm 0.2$ & $1.2 \pm 0.2$ & $1.0 \pm 0.5$ \\
Temperature $\left({ }^{\circ} \mathrm{C}\right)$ & $70 \pm 5$ & $60 \pm 5$ & Room temp. \\
Time $(\mathbf{m i n})$ & $25 \pm 5$ & $15 \pm 5$ & 5 \\
Stability of the product $(\mathbf{m i n})$ & 60 & At least 60 & At least 60 \\
Diluting solvent & methanol & water & water \\
$\boldsymbol{\lambda}_{\max }(\mathbf{n m})$ & 472 & 378 & 374 \\
\hline
\end{tabular}

\section{Accuracy}

To test the validity of the proposed methods they were applied to the determination of pure sample of ALD over the concentration ranges cited in Table 3 . The results obtained were in good agreement with those obtained using the comparison spectrophotometric method. Student $t$-test and the variance ratio $F$-test [45] revealed no significance differences between the performance of the proposed and comparison methods regarding the accuracy and precision, respectively (Table 3). The spectrophotometric comparison method [7] depends on determination of the studied drug through oxidation with ceric sulfate in $0.5 \mathrm{M}$ sulfuric acid and subsequent measurement of the excess unreacted cerium (IV) sulfate at $320 \mathrm{~nm}$.

\section{Precision}

i. Repeatability The repeatability was tested by applying the proposed methods for the determination of three concentrations of ALD in pure form for three successive times. The results are presented in Table 4.

ii. Intermediate precision Intermediate precision was tested by repeated analysis of ALD in pure form using the concentrations shown in Table 4 over a period of three successive days. The results are also summarized in Table 4.

\section{Robustness}

The robustness of the proposed methods is demonstrated by the constancy of the absorbance with the deliberated minor changes in the experimental parameters such as change in $\mathrm{pH}(10.7 \pm 0.2)$, change in the volume of buffer $(1 \pm 0.5 \mathrm{~mL})$, change in the volume of $0.2 \% \mathrm{w} / \mathrm{v}$ NBD-Cl $(1.2 \pm 0.2)$, change in the heating temperature $\left(70 \pm 3^{\circ} \mathrm{C}\right)$ and change in the heating time, $25 \pm 5$ min for method I. Meanwhile, for method II these changes include; change in $\mathrm{pH}(10.5 \pm 0.5)$, change in the volume of the buffer 
Table 3 Application of the proposed and comparison methods to the determination of ALD in pure form

\begin{tabular}{lcccc}
\hline Parameter & Method I & Method II & Method III & Comparison Method (7) \\
\hline No of experiments & 6 & 5 & 6 & 3 \\
$\mathbf{X} \pm$ S.D. & $100.47 \pm 1.12$ & $100.17 \pm 1.21$ & $99.23 \pm 1.26$ & $100.55 \pm 1.30$ \\
$\mathbf{t}$ & $0.096(2.365)^{*}$ & $0.420(2.447)^{*}$ & $1.471(2.365)^{*}$ & \\
$\mathbf{F}$ & $1.347(5.786)^{*}$ & $1.154(6.944)^{*}$ & $1.064(5.786)^{*}$ & \\
\hline
\end{tabular}

Each result is the average of three separate determinations

*Values between brackets are the tabulated $\mathrm{t}$ and $\mathrm{F}$ values, at $P=0.05$ [45].

Table 4 Precision data of the proposed methods for the determination of ALD in pure form

\begin{tabular}{|c|c|c|c|c|c|c|}
\hline \multirow[t]{2}{*}{ Parameter } & \multicolumn{3}{|c|}{ Intra - day precision } & \multicolumn{3}{|c|}{ Inter - day precision } \\
\hline & Conc. taken $(\mu \mathrm{g} / \mathrm{ml})$ & Conc. found $(\mu \mathrm{g} / \mathrm{ml})$ & $\%$ Found & Conc. taken $(\mu \mathrm{g} / \mathrm{ml})$ & Conc. found $(\mu \mathrm{g} / \mathrm{ml})$ & $\%$ Found \\
\hline & 5.00 & 4.927 & 98.50 & 5.00 & 4.948 & 98.96 \\
\hline \multirow[t]{2}{*}{ Method I } & 10.00 & 9.958 & 99.58 & 10.00 & 9.999 & 99.99 \\
\hline & 15.00 & 15.022 & 100.17 & 15.00 & 15.138 & 100.92 \\
\hline$-x \pm S D$ & & & $99.42 \pm 0.85$ & & & $99.96 \pm 0.98$ \\
\hline$\%$ RSD & & & 0.85 & & & 0.98 \\
\hline \multirow[t]{2}{*}{$\% \mathrm{Er}$} & & & 0.49 & & & 0.57 \\
\hline & 12.00 & 11.97 & 99.73 & 12.00 & 11.88 & 98.99 \\
\hline \multirow[t]{2}{*}{ Method II } & 16.00 & 16.26 & 101.63 & 16.00 & 15.84 & 99.01 \\
\hline & 20.00 & 20.42 & 102.13 & 20.00 & 19.96 & 99.81 \\
\hline$-x \pm S D$ & & & $101.16 \pm 1.27$ & & & $99.27 \pm 0.47$ \\
\hline$\%$ RSD & & & 1.26 & & & 0.47 \\
\hline \multirow[t]{2}{*}{$\% \mathrm{Er}$} & & & 0.73 & & & 0.27 \\
\hline & 3.00 & 2.978 & 99.28 & 3.00 & 2.957 & 98.55 \\
\hline \multirow[t]{2}{*}{ Method III } & 15.00 & 14.928 & 99.52 & 15.00 & 14.987 & 99.91 \\
\hline & 30.00 & 30.096 & 100.32 & 30.00 & 29.926 & 9975 \\
\hline$-x \pm S D$ & & & $99.71 \pm 0.54$ & & & $99.40 \pm 0.74$ \\
\hline$\%$ RSD & & & 0.54 & & & 0.74 \\
\hline$\% \mathrm{Er}$ & & & 0.31 & & & 0.43 \\
\hline
\end{tabular}

Table 5 Application of the proposed and comparison methods to the determination of ALD in tablet dosage forms

\begin{tabular}{|c|c|c|c|c|c|c|c|}
\hline \multirow{2}{*}{$\begin{array}{l}\text { Pharmaceutical } \\
\text { preparation }\end{array}$} & \multicolumn{2}{|l|}{ Method I } & \multicolumn{2}{|l|}{ Method II } & \multicolumn{2}{|l|}{ Method III } & \multirow{2}{*}{$\begin{array}{c}\text { Comparison method } \\
\text { (7) }\end{array}$} \\
\hline & $\begin{array}{l}\text { Conc. taken }(\mu \mathrm{g} / \\
\mathrm{mL})\end{array}$ & $\begin{array}{c}\% \\
\text { Found }\end{array}$ & $\begin{array}{c}\text { Conc. taken }(\mu \mathrm{g} / \\
\mathrm{mL})\end{array}$ & $\begin{array}{c}\% \\
\text { Found }\end{array}$ & $\begin{array}{c}\text { Conc. taken }(\mu \mathrm{g} / \\
\mathrm{mL})\end{array}$ & $\begin{array}{c}\% \\
\text { Found }\end{array}$ & \\
\hline Osteonate ${ }^{\circledR}$ tablets & 10.00 & 99.24 & 16.00 & 99.92 & 18.00 & 98.17 & 101.16 \\
\hline $\begin{array}{l}\text { (13.05 mg } \\
\text { ALD/tablet) }^{\mathrm{a}}\end{array}$ & $\begin{array}{l}15.00 \\
20.00\end{array}$ & $\begin{array}{l}98.41 \\
97.51\end{array}$ & $\begin{array}{l}20.00 \\
40.00\end{array}$ & $\begin{array}{l}97.50 \\
99.08\end{array}$ & $\begin{array}{l}24.00 \\
30.00\end{array}$ & $\begin{array}{c}97.88 \\
100.70\end{array}$ & $\begin{array}{c}102.67 \\
99.65\end{array}$ \\
\hline${ }^{-} x \pm$ S.D. & \multicolumn{2}{|c|}{$98.39 \pm 0.87$} & \multicolumn{2}{|c|}{$98.83 \pm 1.23$} & \multicolumn{2}{|c|}{$98.92 \pm 1.55$} & $101.16 \pm 1.51$ \\
\hline $\mathbf{t}$ & \multicolumn{2}{|c|}{$2.756(2.776)^{*}$} & \multicolumn{2}{|c|}{$2.073(2.776)^{*}$} & \multicolumn{2}{|c|}{$1.792(2.776)^{*}$} & \\
\hline$F$ & \multicolumn{2}{|c|}{$3.012(19.00)^{*}$} & \multicolumn{2}{|c|}{$1.507(19.00)^{*}$} & \multicolumn{2}{|c|}{$1.064(19.00)^{*}$} & \\
\hline Alendex ${ }^{\circledR}$ tablets & 10.00 & 101.67 & 16.00 & 100.25 & 18.00 & 101.67 & 97.21 \\
\hline $\begin{array}{l}(52.2 \mathrm{mg} \\
\text { ALD/tablet })^{\mathrm{b}}\end{array}$ & $\begin{array}{l}15.00 \\
20.00\end{array}$ & $\begin{array}{c}98.32 \\
100.34\end{array}$ & $\begin{array}{l}20.00 \\
40.00\end{array}$ & $\begin{array}{l}99.83 \\
98.85\end{array}$ & $\begin{array}{l}24.00 \\
30.00\end{array}$ & $\begin{array}{l}98.65 \\
99.81\end{array}$ & $\begin{array}{c}101.00 \\
99.25\end{array}$ \\
\hline${ }^{-} x \pm$ S.D. & \multicolumn{2}{|c|}{$100.11 \pm 1.67$} & \multicolumn{2}{|c|}{$99.64 \pm 0.72$} & \multicolumn{2}{|c|}{$100.04 \pm 1.52$} & $99.15 \pm 1.90$ \\
\hline $\mathrm{t}$ & \multicolumn{2}{|c|}{$0.655(2.776)^{*}$} & \multicolumn{2}{|c|}{$0.409(2.776)^{*}$} & \multicolumn{2}{|c|}{$0.422(2.776)^{*}$} & \\
\hline$F$ & \multicolumn{2}{|c|}{$1.294(19.00)^{*}$} & \multicolumn{2}{|c|}{$6.964(19.00)^{*}$} & \multicolumn{2}{|c|}{$1.054(19.00)^{*}$} & \\
\hline
\end{tabular}

Each result is the average of three separate determinations

*Values between brackets are the tabulated $\mathrm{t}$ and $\mathrm{F}$ values, at $p=0.05$ [45] 

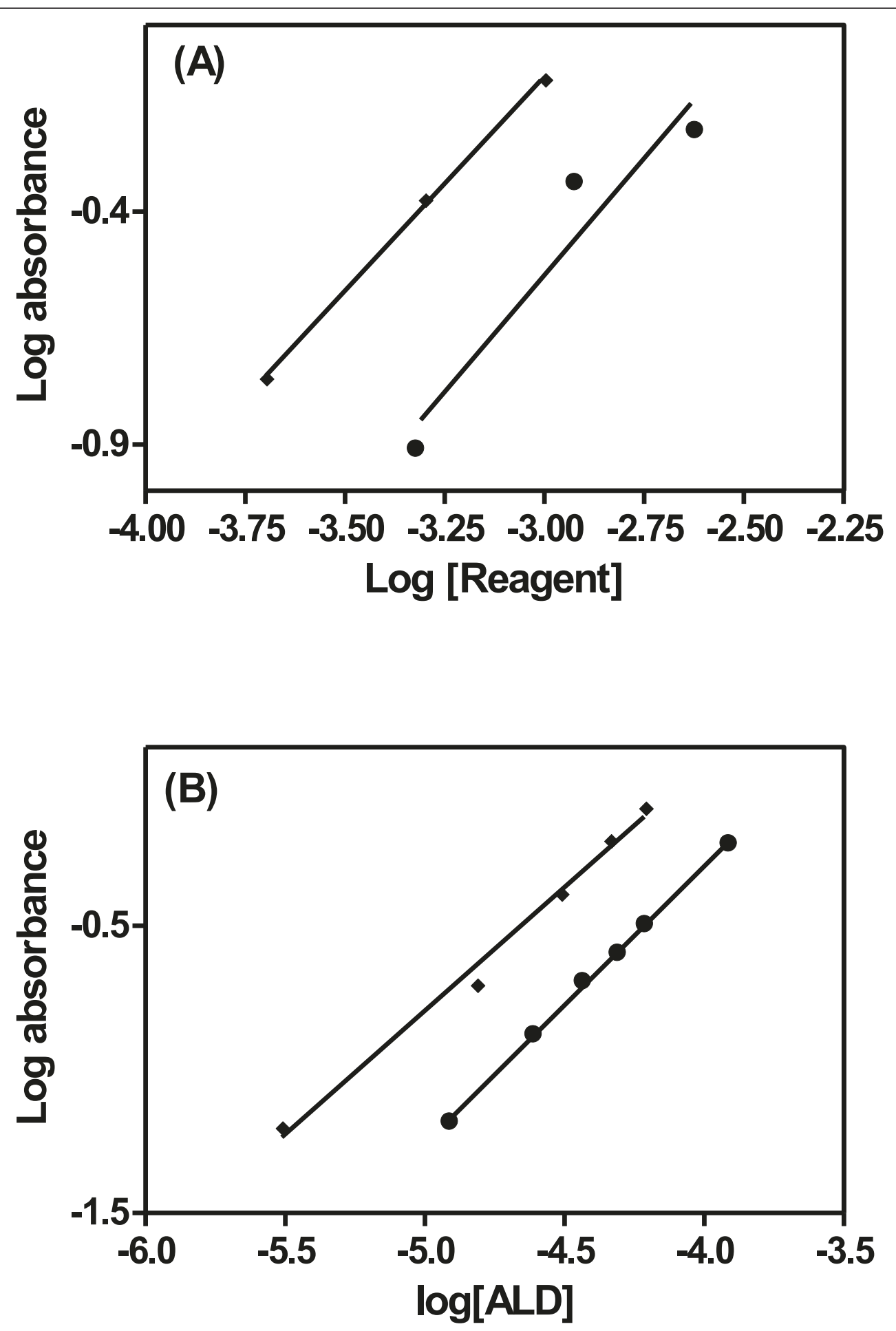

Figure 9 Limiting logarithmic plots for the molar reactivity of ALD with the two proposed reagents: (A) log A vs log [reagent] with [ALD] kept constant; (B) $\log A$ vs log [ALD] with [reagent] kept constant; Where, - Method I (NBD-CI method), and • Method II (DNFB method).

$(1 \pm 0.5 \mathrm{~mL})$, change in the volume of $0.3 \% \mathrm{v} / \mathrm{v}$ DNFB $(1.2 \pm 0.2 \mathrm{~mL})$, change in the heating temperature $(60 \pm$ $\left.5^{\circ} \mathrm{C}\right)$ and change in the heating time $(15 \pm 5 \mathrm{~min})$. For method III these changes include; change in $\mathrm{pH}(10.0 \pm$ $0.5)$, change in the volume of the buffer $(1 \pm 0.5 \mathrm{~mL})$, change in the volume of $0.3 \% \mathrm{v} / \mathrm{v}$ DNFB solution $(1.0 \pm$ 
$0.5 \mathrm{~mL}$ ), and change in the volume of $1 \% \mathrm{w} / \mathrm{v}$ cetrimide solution $(0.8 \pm 0.3 \mathrm{~mL})$. These minor changes that may take place during the experimental operation didn't affect the absorbance of the reactions products.

\section{Specificity}

The specificity of the methods was investigated by observing any interference encountered from the common tablet excipients. These excipients did not interfere with the proposed methods.

\section{Pharmaceutical applications}

The proposed methods were successfully applied to determine the studied drug in its pharmaceutical preparations. The results obtained were statistically compared to those of a reported method [7] by student's $t$ test and variance ratio $F$-test as shown in Table 5 . The experimental values of $t$ and $F$ did not exceed the theoretical values, indicating lack of significant difference between the compared methods.

\section{Molar ratio and mechanism of the proposed reactions}

The stoichiometry of the two reactions was studied adopting the limiting logarithmic method [46]. For the two reactions, two straight lines were obtained using increasing concentrations of the reagent while keeping the concentration of the drug constant and using increasing concentrations of the drug while keeping the concentration of the reagent constant. Plots of log absorbance versus log [NBD-Cl] and log [ALD] gave two straight lines, the slopes of which were 0.9208 / 0.8597, respectively (Figure 9). Hence, it is concluded that the reaction proceeds in the ratio of $1: 1$, confirming that one molecule of the drug condenses with one molecule of NBD-Cl.

Method II was applied for the determination of the stoichiometry of the reaction of ALD and DNFB. Plots of $\log$ absorbance versus $\log$ [DNFB] and $\log$ [ALD] gave straight lines; the values of their slopes were 0.9157 and 0.9666, respectively (Figure 9). Hence, it is concluded that the reaction proceeds in the ratio of $1: 1$, confirming that one molecule of the drug condenses with one molecule of DNFB.

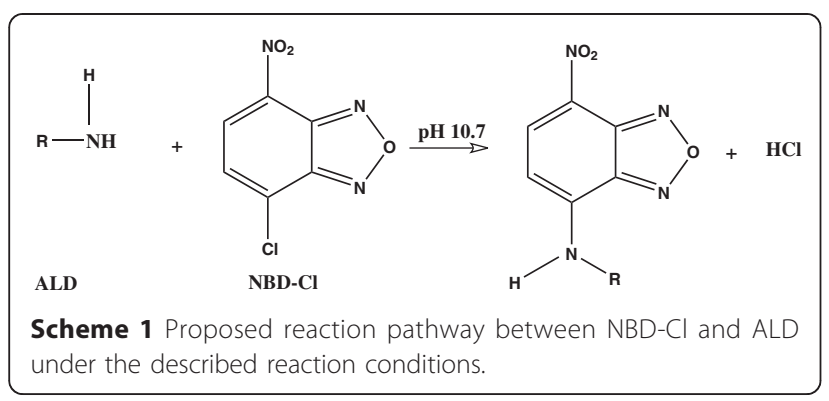

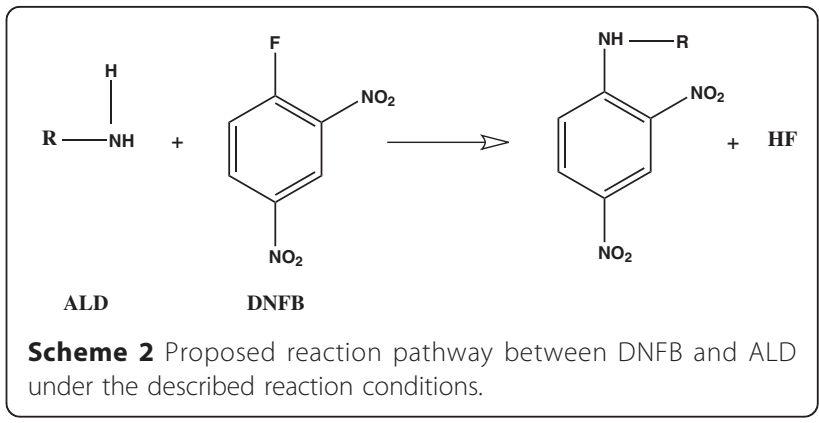

Based on the observed molar ratios, proposed reaction pathways are given in schemes 1 and 2, respectively.

The micellar catalytic effect of the cationic surfactant, cetrimide, on the reaction of ALD with DNFB may be explained on the basis of electrostatic interactions. ALD features 5 negative charges, so it will be electrostatically attracted to the oppositely charged micelles of cetrimide, and thereby brought closer to DNFB reagent that's preferentially solubilized by the micelles, thus contributing to acceleration of the reaction [47].

\section{Critical comparison of the three developed methods}

The critical comparison of the three developed spectrophotometric methods for the determination of ALD leads to the following advantages/disadvantages:

1. All methods are sufficiently sensitive and selective for the determination of the analyte in its pharmaceutical formulations.

2. The linearity and sensitivity are best for Method I. Meanwhile, method I and method III offer the widest determination range $(1.0-20.0 \mu \mathrm{g} / \mathrm{mL}$ for method I and $1.5-30.0 \mu \mathrm{g} / \mathrm{mL}$ for method III).

3. The third method offers the shortest reaction time (5 min)

4. The second and third methods employ simpler diluting solvent (water versus methanol for third method) providing cost effectiveness

Other techniques such as capillary electrophoresis and HPLC may also give good results but, because of the low cost and ease of carrying out the spectrophotometric methods, the

proposed procedures are likely to be very suitable for the quality control of ALD in tablet dosage form.

\section{Conclusion}

The proposed spectrophotometric methods provided sensitive, specific and inexpensive analytical procedures for determination of the non-chromophoric drug alendronate either per se or in its tablet dosage forms without interference from common excipients. Moreover, the developed methods are less time-consuming and do not require elaborate treatments associated with chromatographic 
methods. These attributes, in addition to the satisfactory sensitivity and reproducibility as well as the convenience and simplicity, make the three proposed methods suitable for routine analysis in quality control laboratories.

\section{Authors' contributions}

MIW supervised the whole study, M.E. -SM participated in supervision, ME participated in the assay design, results discussion, and preparing the manuscript. RNE suggested the idea of the assay, conducted practical work and prepared the draft version of the manuscript. All authors read and approved the final manuscript.

\section{Competing interests}

The authors declare that they have no competing interests.

Received: 6 December 2011 Accepted: 2 April 2012

Published: 2 April 2012

\section{References}

1. Goodman LS, Gilman A: The pharmacological Basis of Therapeutics. 10 edition. McGraw Hill, Medical Publication Division, New York; 2001, 1733-1735.

2. Sweetman S: Martindale, The Complete Drug Reference London: The Pharmaceutical Press; 2009, (Electronic version).

3. The British Pharmacopoeia, Her Majesty's Stationary Office, London. 2007, (Electronic Version).

4. The United States Pharmacopoeia $30^{\text {th }}$ and The National formulary $25^{\text {th }}$, Rockville, MD, USA. 2007, (Electronic Version).

5. Koba M, Koba K, Przyborowski L: Application of UV-derivative spectrophotometry for determination of some bisphosphonates drugs in pharmaceutical formulations. Acta Pol Pharm 2008, 65(3):289-294.

6. Kuljanin J, Janković I, Nedeljković J, Prstojević D, Marinković V: Spectrophotometric determination of alendronate in pharmaceutical formulations via complex formation with Fe(III) ions. J Pharm Biomed Anal 2002, 28(6):1215-1220.

7. Taha EA, Youssef NF: Spectrophotometric determination of some drugs for osteoporosis. Chem Pharm Bull 2003, 51(12):1444-1447.

8. Raza A, Zia-ul-Haq M: Application of Certain $\pi$-Acceptors for the Spectrophotometric Determination of Alendronate Sodium in Pharmaceutical Bulk and Dosage Forms. Int J Anal Chem 2011, (doi:10.1155/2011/680902).

9. Al Deeb SK, Hamdan II, Al Najjar SM: Spectroscopic and HPLC methods for the determination of alendronate in tablets and urine. Talanta 2004, 64(3):695-702.

10. De-Haro-Moreno A, Redigolo-pezza H, Pezza L: Potentiometric determination of alendronate in pharmaceutical formulations. Chem Anal 2004, 49(3):351-357.

11. Podolska M, Białecka W, Kwiatkowska-Puchniarz B, Tuszyńska E: Analysis of selected diphosphonic acid derivatives used in treatment of osteoporosis. Part I. Complexometric determination of diphosphonic acid derivatives. Acta Pol Pharm 1997, 54(4):267-272.

12. Podolska M, Białecka W, Kwiatkowska-Puchniarz B: Complexometric determination of diphosphonic acid derivatives. Part II. Acta Pol Pharm 2000, 57(3):159-165.

13. Fernandes C, Leite RS, Lanças FM: Rapid determination of bisphosphonates by ion chromatography with indirect UV detection. Chromatogr Sci 2007, 45(5):236-241.

14. Tsai EW, Chamberlin SD, Forsyth RJ, Bell C, Ip DP, Brooks MA: Determination of bisphosphonate drugs in pharmaceutical dosage formulations by ion chromatography with indirect UV detection. J Pharm Biomed Anal 1994, 12(8):983-991.

15. Tsai EW, Ip DP, Brooks MA: Determination of alendronate in pharmaceutical dosage formulations by ion chromatography with conductivity detection. J Chromatogr 1992, 596(2):217-224.

16. Han $Y H R$, Qin XZ: Determination of alendronate sodium by ion chromatography with refractive index detection. J Chromatogr A 1996 719(2):345-352.

17. Yun MH, Kwon Kl: High-performance liquid chromatography method for determining alendronate sodium in human plasma by detecting fluorescence: Application to a pharmacokinetic study in humans. J Pharm Biomed Anal 2006, 40(1):168-172.

18. Ban E, Park JY, Kim HT, Kim CK: Determination of alendronate in low volumes of plasma by column-switching high-performance liquid chromatography method and its application to pharmacokinetic studies in human plasma. Arch Pharm Res 2011, 34(12):2079-2086.

19. Kwong E, Chiu AM, McClintock SA, Cotton ML: HPLC analysis of an amino bisphosphonate in pharmaceutical formulations using postcolumn derivatization and fluorescence detection. J Chromatogr Sci 1990, 28(11):563-566.

20. Kline WF, Matuszewski BK: Improved determination of the bisphosphonate alendronate in human plasma and urine by automated precolumn derivatization and high-performance liquid chromatography with fluorescence and electrochemical detection. J Chromatogr 1992, 583(2):183-193.

21. Zhu LS, Lapko VN, Lee JW, Basir YJ, Kafonek C, Olsen R, Briscoe CA: A general approach for the quantitative analysis of bisphosphonates in human serum and urine by high-performance liquid chromatography/ tandem mass spectrometry. Rapid Commun Mass Spectrom 2006, 20(22):3421-3426.

22. Tarcomnicu I, Silvestro L, Savu SR, Gherase A, Dulea C: Development and application of a high-performance liquid chromatography-mass spectrometry method to determine alendronate in human urine. $J$ Chromatogr A 2007, 1160(1-2):21-33.

23. Qin XZ, Tsai EW, Sakuma T, Ip DP: Pharmaceutical application of liquid chromatography-mass spectrometry: Il.1 lon chromatography -ion spray mass spectrometric characterization of alendronate. J Chromatogr A 1994, 686(2):205-212.

24. Su SW, Liao YC, Whang CW: Analysis of alendronate in human urine and plasma by magnetic solid-phase extraction and capillary electrophoresis with fluorescence detection. J Sep Sci 2012, (DOI: 10.1002/jssc.201100824).

25. Bexheti D, Anderson El, Hutt AJ, Hanna-Brown M: Evaluation of multidimensional capillary electrophoretic methodologies for determination of amino bisphosphonate pharmaceuticals. J Chromatogr A 2006, 1130(1):137-144.

26. Tsai EW, Sing MM, Lu HH, Ip DP, Brooks MA: Application of capillary electrophoresis to pharmaceutical analysis: Determination of alendronate in dosage forms. J Chromatogr 1992, 626(2):245-250

27. Tzanavaras PD, Zacharis CK, Theodoridis GA, Kalaitzantonakis EA Voulgaropoulos AN: Normal spectrophotometric and stopped-flow spectrofluorimetric sequential injection methods for the determination of alendronic acid, an anti-osteoporosis amino-bisphosphonate drug, in pharmaceuticals. Anal Chim Acta 2005, 547(1):98-103.

28. Pesez M, Batros J: Colorimetric and fluorimetric Analysis of Organic Compounds and Drugs New York: Marcel Dekker Inc; 1974, 128-132, 170

29. Ulu ST: Spectrophotometric and spectrofluorimetric determination of atomoxetine in pharmaceutical preparations. Pharmazie 2011, 66(11):831-835.

30. Gouda AA, Hashem H, Hassan W: Spectophotometric methods for determination of cefdinir in pharmaceutical formulations via derivatization with 1,2-naphthoquinone-4-sulfonate and 4-chloro-7nitrobenzo-2-oxa-1,3-diazole. Drug Test Anal 2011, (doi: 10.1002/dta.280).

31. Walash MI, Belal FF, El-Enany N, Elmansi H: Development and validation of stability indicating method for determination of sertraline following $\mathrm{ICH}$ guidlines and its determination in pharmaceuticals and biological fluids. Chem Cent J 2011, 5:61.

32. Walash MI, Belal F, El-Enany N, Elmansi H: Spectrofluorimetric determination of paroxetine $\mathrm{HCl}$ in pharmaceuticals via derivatization with 4-chloro-7- nitrobenzo-2-oxa-1,3-diazole (NBD-Cl). J Fluoresc 2011, 21(1):105-112.

33. El-Enany N, El-Sherbiny D, Belal F: Spectrophotometric, Spectrofluorometric and HPLC Determination of Desloratadine in Dosage Forms and Human Plasma. Chem Pharm Bull 2007, 55(12):1662-1670.

34. Anis SM, Hosny MM, Abdellatef HE, El-Balkiny MN: Kinetic spectrophotometric determination of betahistine dihydrochloride and etilefrine hydrochloride in pharmaceutical formulation. Pharm Anal Acta 2011, 2:116, doi:10.4172/2153-2435.1000116

35. Walash MI, Belal FF, El-Enany N, El-Maghrabey MH: Utility of certain nucleophilic aromatic substitution reactions for the assay of pregabalin in capsules. Chem Cent J 2011, 5:36. 
36. Belal SF, Haggag RS, Shaalan RA: The use of an aromatic substitution reaction in the spectrophotometric determination of selected amino or thiol containing drugs. J Food Drug Anal 2008, 16(1):26-33.

37. Van der Horst FA, Teeuwsen J, Holthuis JJ, Brinkman UA: High-performance liquid chromatographic determination of amantadine in urine after micelle-mediated pre-column derivatization with 1-fluoro-2,4dinitrobenzene. J Pharm Biomed Anal 1990, 8(8-12):799-804.

38. Van der Horst FA, Holthuis Jj: Study of the derivatization of $\mathrm{n}$-alkylamines with 1-fluoro-2,4-dinitrobenzene in the presence of aqueous cetyltrimethylammonium bromide micelles. J Chromatogr 1988, 426(2):267-282.

39. Kottke $D$, Beyrich $T$, Friedrich $W$ : The micelle catalysis of cetyltrimethyl ammonium bromide on phenylalanine arylation by 2,4dinitrofluorobenzene. Pharmazie 1985, 40(6):395-397.

40. Perrin DD, Dempsey B: Buffers for pH and Metal Ion Control Wiley, New York; 1974, 147, Chap. 10 App. II.

41. Miyano H, Toyo'oka T, Imai K: Further studies on the reaction of amines and proteins with 4-fluoro-7-nitrobenzo-2-oxa-1,3-diazole. Anal Chim Acta 1985, 170:81-87.

42. Imai K, Toyo'oka T, Miyano H: Fluorigenic reagents for primary and secondary amines and thiols in high-performance liquid chromatography. A review. Analyst 1984, 109(11):1365-1373.

43. Connor KA: Reaction Mechanisms in Organic Analytical Chemistry New York USA: Wiley; 1973, 274.

44. ICH Harmonized Tripartite Guideline, Validation of Analytical Procedures: Text and Methodology, Q2 (R1), Current Step 4 Version, Parent Guidelines on Methodology Dated November 6 1996, Incorporated in November 2005.[http://www.fda.gov/downloads/Regulator\% 20yInformation/Guidances/UCM128049.pdf], (accessed February15, 2008).

45. Miller JC, Miller JN: Statistics and Chemometrics for Analytical Chemistry. 5 edition. Pearson Education Limited: Harlow, England; 2005, 256.

46. Rose J: Advanced Physico-Chemical Experiments London: Pitman;1964.

47. Esteve-Romero JS, Simo-Alfonso EF, Garcia-Alvarez-Coque MC, RamisRamos G: Micellar enhanced spectrophotometric determination of organic species. TrAC 1995, 14(1):29-37.

doi:10.1186/1752-153X-6-25

Cite this article as: Walash et al:: Validated spectrophotometric methods for determination of Alendronate sodium in tablets through nucleophilic aromatic substitution reactions. Chemistry Central Journal $20126: 25$.

Publish with ChemistryCentral and every
scientist can read your work free of charge
"Open access provides opportunities to our
colleagues in other parts of the globe, by allowing
anyone to view the content free of charge."
W. Jeffery Hurst, The Hershey Company.
- available free of charge to the entire scientific community
- peer reviewed and published immediately upon acceptance
- cited in PubMed and archived on PubMed Central
- yours - you keep the copyright
Submit your manuscript here:
http://www.chemistrycentral.com/manuscript/

